\title{
Retraction Note to: A Computer Vision-Based Approach for Subspace Clustering and Lagrange Multiplier Optimization in High-Dimensional Data
}

\author{
K. R. Radhika, C. N. Pushpa, J. Thriveni, and K. R. Venugopal
}

\section{Retraction Note to: \\ Chapter "A Computer Vision-Based Approach for Subspace Clustering and Lagrange Multiplier Optimization in High-Dimensional Data" in: S. Fong et al. (eds.), ICT Analysis and Applications, Lecture Notesin Networks and Systems 154, https://doi.org/10.1007/978-981-15-8354-4_14}

The publisher would like to alert readers that the conference paper [1] was retracted because of a production error resulting in duplicate publication in the same book series in different volumes. The correct citation for this article should be from the original publication [2].

[1] Radhika K.R., Pushpa C.N., Thriveni J., Venugopal K.R. (2021) A Computer Vision-Based Approach for Subspace Clustering and Lagrange Multiplier Optimization in High-Dimensional Data. In: Fong S., Dey N., Joshi A. (eds) ICT Analysis and Applications. Lecture Notes in Networks and Systems, vol 154. Springer, Singapore. https://doi.org/10.1007/978-981-15-8354-4_14

[2] Radhika K.R., Pushpa C.N., Thriveni J., Venugopal K.R. (2020) A Computer Vision Based Approach for Subspace Clustering and Lagrange Multiplier Optimization in High-Dimensional Data. In: Fong S., Dey N., Joshi A. (eds) ICT Analysis and Applications. Lecture Notes in Networks and Systems, vol 93. Springer, Singapore. https://doi.org/10.1007/978-981-15-0630-7_43

The retracted version of this chapter can be found at https://doi.org/10.1007/978-981-15-8354-4_14 